\title{
Elicited bid functions in (a)symmetric first-price auctions*
}

\author{
Paul Pezanis-Christou and Abdolkarim Sadrieh
}

June 4, 2003

\begin{abstract}
We report on a series of experiments that examine bidding behavior in first-price sealed bid auctions with symmetric and asymmetric bidders. To study the extent of strategic behavior, we use an experimental design that elicits bidders' complete bid functions in each round (auction) of the experiment. In the aggregate, behavior is consistent with the basic equilibrium predictions for risk neutral or homogenous risk averse bidders (extent of bid shading, average seller's revenues and deviations from equilibrium). However, when we look at the extent of best reply behavior and the shape of bid functions, we find that individual behavior is not in line with the received equilibrium models, although it exhibits strategic sophistication.
\end{abstract}

\section{JEL Codes:}

D44, C9

\section{Keywords :}

Asymmetric first-price auctions, private independent values, elicited bid functions, constant relative risk aversion, empirical best replies, experimental methods

\author{
Affiliations \\ Paul Pezanis-Christou \\ Institut d'Analisi Economica (CSIC) \\ Campus UAB \\ 08193 Bellaterra \\ Barcelona, Spain \\ ppc@iae.csic.es
}

\author{
Abdolkarim Sadrieh \\ Department of Economics and CentER \\ Tilburg University \\ PO Box 90153 \\ 5000 LE Tilburg, The Netherlands \\ sadrieh@uvt.nl
}

\footnotetext{
* We thank Reinhard Selten and seminar participants at Tilburg University, University of Magdeburg, and at the Economic Science Association Conference for helpful comments. This research benefited from financial support from the European Commission through a TMR-ENDEAR Network Grant (FMRX-CT98-0238) and a Marie Currie Fellowship (Sadrieh: HPMF-CT-199-00312) and from the Deutsche Forschungsgemeinschaft through SFB 303.
} 
Since the seminal contributions of Vickrey (1961) and Milgrom and Weber (1982) much of the theoretical literature on auctions has focused on the allocative properties of mechanisms that involve either weakly dominant bidding strategies, such as the ascending-price auction, or the Nash equilibrium concept, such as the first-price sealed bid auction. From a practical standpoint, however, while weakly dominant strategies are relatively straightforward to figure out and thus very likely to be used, the rationality assumptions underlying the definition of Nash equilibrium type of strategies may cast some doubt about their empirical observation.

For the simplest case of single-unit auctions with private independent values and symmetric bidders, evidence from laboratory experiments shows that the revenue and bid predictions for first-price sealed bid auctions are systematically violated, mostly because subjects tend to bid above the risk neutral Nash equilibrium prediction. Cox, Roberson and Smith (1982) and Cox, Smith and Walker (1988) explain such overbidding in terms of a Nash equilibrium model that assumes constant relative risk averse bidders (the CRRA model) and numerous studies have been conducted to further assess this model. ${ }^{1}$ While these studies find a remarkable support for the CRRA model of bidding, they do not assess the underlying assumption of a strategic behavior. Chen and Plott (1998) observe in particular that if bidders' valuations are uniformly distributed, as it is usually the case in auction experiments, then the Nash equilibrium strategies are linear and, hence, impossible to disentangle from linear ad hoc bidding rules such as a percentage markdown strategy. They report on a series of experiments for which the Nash equilibrium predictions are nonlinear and show that the CRRA model is outperformed by a non-linear ad hoc model. However, their study also indicates that a belief-free version of the CRRA model (i.e., which does not restrict the subjects' beliefs about the distribution of

\footnotetext{
${ }^{1}$ See Kagel (1995) for an overview. See Goeree, Holt and Palfrey (2002) for an assessment of behavior in these auctions in terms of a quantal response equilibrium.
} 
risk parameters) explains the data slightly better than this nonlinear ad hoc model so that even in this nonlinear setting, the distinction between game theoretic predictions and those of $a d$ hoc models is not stark and, as Chen and Plott (1998) note, it may be sensitive to the statistical specifications of the model.

In this paper, we report an experimental study of behavior in first-price sealed bid auctions with symmetric and with asymmetric bidders (i.e., bidders who draw their valuations with replacement from different distributions). We study the independent private value framework using the theoretical benchmark provided by Maskin and Riley (2000a) in which bidders are either Weak or Strong, with the former being more likely to draw lower values than the latter. The goal of our analysis is twofold. First, we are interested to check whether the strategic considerations that drive the Nash equilibrium outcomes of Vickrey (1961), Cox et al. (1982, 1988) and Maskin and Riley (2000a) are observed under laboratory conditions. Such considerations include the shape of bid functions and the extent of best reply bidding. For the asymmetric settings that we consider, the equilibrium bid functions for Weak and Strong bidders are nonlinear in values and convey well how each type of bidder should optimally react to his/her rival. Therefore, we can easily assess whether bidders perceived the strategic implications of their respective value distributions. Second, we are interested to find out whether the overbidding observed in symmetric settings is also observed in the more realistic case of asymmetric auctions. Güth, Ivanova-Stenzel and Wolfstetter (2002) and PezanisChristou (2002) report experimental evidence that this is generally the case but they do not assess this overbidding in terms of equilibrium bidding with constant relative risk preferences. Interestingly, the effect of such preferences on bidders' behavior can explain overbidding in asymmetric auction settings, but only over a range of high values. Therefore, by tracking behavior across different bidding environments we provide a broader picture of the constant relative risk aversion hypothesis as an explanation for overbidding in first-price auctions. 
A major problem with assessing the extent of strategic behavior in standard auction experiments is the stochastic structure of the experiment: in each round, there is only one winner and each bidder receives a new value and is asked to submit one bid. Hence, the behavior observed in these experiments can be influenced by the history of the game (e.g., the realization of valuations and the number of times a bidder won the auction). To circumvent this problem, we use a design that induces a bidder to think how to bid for each possible valuation that she/he may receive instead of for one specific valuation that she/he receives. This design (which is explained in section 3) was proposed by Selten and Buchta (1998) and consists in asking each subject to submit a complete bid function (i.e., that produces a bid for each possible value) before she/he receives her/his private value. Since this change in bidders' response mode does not affect the information structure or the strategic implications of bidding in first-price auctions, we believe that it can provide helpful insights into bidders' strategic behavior.

Our results indicate that the submitted bid functions support the basic behavioral and revenue predictions of the Nash equilibrium models for symmetric and asymmetric auctions. Bidding behavior in the symmetric auctions can be explained by the CRRA model that assumes homogenous bidders whereas in the asymmetric auctions, it is equally well explained by the standard Nash equilibrium model for risk neutral bidders as by the CRRA model for homogenous bidders. However, when we check the shape of individual bid functions, we find that in the symmetric framework, the predominant submission of concave bid functions does not support the predictions of the CRRA model for homogenous or heterogeneous risk averse bidders. Nevertheless, about $60 \%$ of all bid functions do match the concave shape of the corresponding best-reply functions, which are concave in $84 \%$ of the time. In the asymmetric treatments, both Strong and Weak bidders overbid mostly at low values, for which they should submit zero bids, whether they are risk neutral or reasonably risk averse. In terms of 
shapes, Nash equilibrium predicts convex bid functions for both Strong and Weak bidders with either type of risk preferences but this is observed about $49 \%$ of the time for Strong bidders and about $25 \%$ of the time for Weak bidders. Further, the shapes of observed bid functions match those of the corresponding best-reply functions about $50 \%$ of the time for both Strong and Weak bidders. Therefore, the outcomes of our experiment suggest that although individual behavior is usually not consistent with the Nash equilibrium predictions for both symmetric and asymmetric first-price auctions, it still displays characteristics of bestreply behavior and it matches the theoretical Nash equilibrium predictions in the aggregate.

The following section outlines the model of Maskin and Riley (2000a) and the theoretical framework we use to analyze data. We determine the Risk Neutral and the Constant Relative Risk Averse Nash Equilibrium bidding strategies for our auction games in Section 2. The experimental procedure is described in Section 3 and we report on the outcomes in Section 4. Section 5 concludes the paper.

\section{Theoretical benchmarks}

The bidding model of Maskin and Riley (2000a) extends the symmetric framework of Vickrey (1961) to asymmetric settings and can be outlined as follows. There are two bidders, $S$ (Strong) and $W$ (Weak), who draw their independent-private values from continuous distributions $F_{S}$ and $F_{W}$ that are defined on $I_{S}=\left[\underline{v}_{S} ; \bar{v}_{S}\right]$ and $I_{W}=\left[\underline{v}_{W} ; \bar{v}_{W}\right]$, respectively. In a first-price auction, if bidder $i$ has value $v_{i}$ and obtains the item with a bid $b_{i}$, she/he pays the price $b_{i}$ and receives the payoff $v_{i}-b_{i}$. A pair of bid functions $\left\{b_{S}(v), b_{W}(v)\right\}$ (with $b_{i}^{\prime}\left(v_{i}\right)>0$, for $\left.i=S, W\right)$ is an equilibrium if $b_{i}\left(v_{i}\right)$ is a best response to $b_{j}\left(v_{j}\right)$ for all $v_{i}$ in $I_{i}$ and all $v_{j}$ in $I_{j}$, with $i \neq j$. Let $\phi_{i}\left(b_{i}\right)=v_{i}$ denote the inverse function of $b_{i}\left(v_{i}\right)$. Bidder $i$ 's expected payoff then has the following expression 


$$
U\left(v_{i}, b\right)=\left(v_{i}-b\right) F_{j}\left(\phi_{j}(b)\right) \quad \text { for } i \neq j=S, W
$$

Since it is not worth bidding more than the maximum possible bid of one's competitor, there must exist some common maximum bid, $\bar{b} .^{2}$ Therefore, in equilibrium, the inverse bid functions must satisfy the following two boundary conditions $\phi_{i}(0)=0$ and $F_{i}\left(\phi_{i}(\bar{b})\right)=1$ for $i=S, W$.

Maskin and Riley (2000a) show that in the Risk Neutral Nash Equilibrium (RNNE), inverse bid functions $\phi_{S}^{*}(b)$ and $\phi_{W}^{*}(b)$ are determined as the solution to the system of non-linear differential equations generated from the first-order conditions of (1) with respect to $b$. If we assume symmetric bidders, then $\quad F_{S}(v)=F_{W}(v)=F(v), \phi_{S}(b)=\phi_{W}(b)=\phi(b) \quad$ and $I_{S} \equiv I_{W} \equiv I=[\underline{v} ; \bar{v}]$ so that (1) has a single first order condition with a unique solution for the boundary condition $\phi(0)=0 .{ }^{3}$ Vickrey (1961) established that the RNNE bidding strategy for symmetric bidders is

$$
b(v)=v-\int_{\underline{v}}^{v} \frac{F(x)}{F(v)} d x
$$

In the case of asymmetric bidders, the system of non-linear differential equations that solve the first-order conditions of (1) usually has no analytical solution and has to be determined numerically. However, if bidders' distributions of values satisfy a few additional assumptions, Maskin and Riley (2000a, Proposition 3.5) predict that in equilibrium, Strong bidders bid less

\footnotetext{
${ }^{2}$ See Plum (1992), Marshall, Meurer, Richard and Stromquist (1995), Corns and Schotter (1998), Landsberger, Rubinstein, Wolfstetter and Zamir (1999), Lebrun (1999) and Li and Riley (1999) for other asymmetric auction models that require a common ceiling on bids.

${ }^{3}$ Maskin and Riley (2000b) show that if bidders are symmetric, then the equilibrium bidding strategy is unique and monotone increasing.
} 
aggressively than Weak bidders, so that $b_{S}(v)<b_{W}(v)$, for all $v \in(0 ; \bar{v})$. In addition, they provide sufficient conditions on the bidders' distributions of values to observe different rankings of first- and second-price auctions in terms of the seller's revenues (see their Propositions 4.3, 4.4 and 4.5). Actually, since it is always a dominant strategy for a bidder to bid her/his own valuation in second-price auctions, these revenue rankings are the results of bidders' equilibrium behavior in first-price auctions. On the one hand, if the valuations of the Strong bidder are all greater than the maximum valuation of the Weak bidder, then the Strong bidder will always outbid the Weak bidder; Maskin and Riley (2000a) refer to this as the "Getty effect". When this happens, second-price auctions yield lower revenues than first-price auctions. On the other hand, if there is a positive probability for the Weak bidder to submit no bid at all (i.e. the range of values of the weak bidder is partially in the negative domain or below the seller's reserve price), then there is an incentive for the Strong bidder to low-ball, i.e., to submit very low bids (close or equal to the seller's reserve price) for a range of low values. It is this incentive to low-ball that makes first-price auctions yield lower expected revenues than second-price auctions. Li and Riley (1999) extend this analysis to asymmetric auctions with more than two bidders, and who may display constant absolute risk averse preferences and/or have affiliated values. One striking result of their analysis is that the effect of low-balling on the seller's expected revenue holds even if bidders are extremely risk averse and have uniformly distributed values.

In what follows, we assume bidders to display homogenous constant relative risk averse preferences. Such preferences are well adapted to auction experiments because they 
encompass risk neutrality as a special case. ${ }^{4}$ In a symmetric setting, the expected utility representation of such preferences is

$$
U\left(v_{i}, b\right)=\left(v_{i}-b\right)^{r} F(f(b)) \quad \text { with } r>0
$$

When $r=1$, (4) characterizes a risk neutral utility function whereas for $r<1$, the marginal utility of an additional unit of income decreases so that bidders' display constant relative risk aversion. The Risk Averse Nash Equilibrium (RANE) bidding strategy for symmetric firstprice auctions with two bidders then takes the following expression

$$
b(v)=v-\int_{\underline{v}}^{v}\left(\frac{F(x)}{F(v)}\right)^{\frac{1}{r}} d x
$$

For asymmetric first-price auctions there usually are no closed-form RANE equilibrium bid functions so that these can only be determined numerically. We derive both the RNNE and RANE bid functions for our asymmetric framework in the next section.

\section{Experimental Design and Procedure}

\subsection{Design}

We consider two-bidder first-price auctions as described in the previous section and we study three treatments: one that involves symmetric bidders and two that involve asymmetric bidders (i.e., a Strong bidder and a Weak bidder). All bidders have their values drawn from uniform distributions. In our symmetric treatment, all bidders draw their values from $I_{S}=$ $[0 ; 100]$. In our asymmetric treatments, the range of values of the Strong bidders is also $I_{S}$ but

\footnotetext{
${ }^{4}$ See Holt and Davis (1995) for an outline on the use of the constant absolute and constant relative risk aversion
} 
the range of values for Weak bidders $I_{W}$ differs across treatments. Table 1 summarizes the treatment parameters and the main characteristics of our experiments.

We use a simplified version of the design proposed by Selten and Buchta (1998) which consists in asking each subject to submit a two-piecewise linear bid function in each round, before receiving the private value..$^{5}$ Since there is no rationale for bidding more than one's value in a first-price sealed-bid auction, subjects were not allowed to chose bid functions that could generate a bid greater than the private value drawn. Also, no bid was allowed for negative values and the submitted bid function had to span the entire range of possible positive values. These conditions imply that the submitted bid function cannot have a nonzero intercept and that bidder $i$ 's task consists in choosing: $i$ ) the coordinates of an interior node $\left(x_{i 1}, y_{i 1}\right)$ that could represent a kink in their bid function, and ii) the bid $y_{i 2}$ corresponding to the highest possible value $\bar{v}_{i}$. With such a design, bidders could choose their bid functions from a set of over half a million possible functions.

As the submitted bid functions are two-piecewise linear instead of differentiable, as in Maskin and Riley (2000a), we need to determine the RNNE and the RANE bidding strategies for the particular strategy space of our experiments. To this end, we use a numerical procedure that traces best reply chains until a rest point is found (Harsanyi and Selten 1988). When deriving

\footnotetext{
concepts in experimental economics.

${ }^{5}$ Selten and Buchta (1998) examine a symmetric setting which involved three bidders who had their values drawn from a uniform distribution on [0;100] and who could submit bid functions that could have up to 10000 segments. Güth, Ivanova-Stenzel, Konigstein and Strobel (2002) use a similar design to compare treatments of symmetric first and second price auctions to first and second price "fair division" games. In their experiments, subjects' private values were drawn (with replacement) from a set of 11 possible valuations $\{50,60,70, \ldots, 150\}$ and the submitted bids had 11 nodes.
} 
the RANE bidding strategies, we treat $r$ as a "natural constant" and set it equal to .5 , which is in the mid-range of the estimates reported in the literature. ${ }^{6}$

Tables 2 and 3 report the nodes corresponding to the RNNE and the RANE bid functions for our three treatments. Note that since in our experiments, bidders' strategies are not differentiable, the common bid ceiling requirement for continuous and differentiable bidding strategies does no more necessarily hold. ${ }^{7}$ Another point worth noting is that the asymmetry in the MIX treatment combines low-balling with the "Getty effect" so that it represents an intermediate case between the LOW treatment in which low-balling is important and the SYM treatment where there is no incentive at all to low-ball. Further, the equilibrium strategy for Strong bidders in MIX is almost identical to the one of Strong bidders in the LOW treatment. However, the equilibrium strategies for Weak bidders are very different across treatments. This allows us to assess both the extent of low-balling by Strong bidders and the response of Weak bidders in different bidding environments.

Table 1 - Treatment Parameters

\begin{tabular}{|cccccc|}
\hline Treatment & $\begin{array}{c}\text { Strong bidder's } \\
\text { range of values } \\
I_{S}=\left[\underline{v}_{S}, \bar{v}_{S}\right]\end{array}$ & $\begin{array}{c}\text { Weak bidder's } \\
\text { range of values } \\
I_{W}=\left[\underline{v}_{W}, \bar{v}_{W}\right]\end{array}$ & $\begin{array}{c}\text { Independent } \\
\text { observations }\end{array}$ & $\begin{array}{c}\text { subjects per } \\
\text { independent } \\
\text { observation }\end{array}$ & $\begin{array}{c}\text { number of rounds } \\
\text { per subject }\end{array}$ \\
\hline LOW & {$[0,+100]$} & {$[-100,+100]$} & 9 & 6 & 100 \\
\hline MIX & {$[0,+100]$} & {$[-75,+75]$} & 9 & 6 & 100 \\
\hline SYM & {$[0,+100]$} & {$[0,+100]$} & 6 & 6 & 100 \\
\hline
\end{tabular}

\footnotetext{
${ }^{6}$ Goeree et al. (2002) report an estimate of .48 for two-bidder auctions. Cox and Oaxaca (1996) and Chen and Plott (1998) report estimates of .33 and .52 for auctions with 4 and 3 bidders, assuming heterogeneous risk preferences. Pezanis-Christou and Romeu (2002) report average estimates of homogenous risk preferences that range between .39 and 1 for auctions with 3,4 and 5 bidders.

${ }^{7}$ The RNNE best response tracing procedure for the LOW treatment converges to a cycle in which the $y_{2}$ coordinates of both bidders switch between 30 and 31 .
} 
Table 2 - Piecewise linear bid functions predicted by the risk neutral Nash equilibrium (RNNE)

\begin{tabular}{|c|cccc|cccc|}
\hline \multirow{2}{*}{ Treatment } & \multicolumn{4}{|c|}{ Strong } & \multicolumn{5}{c|}{ Weak } \\
& $\left(x_{1}^{*}, y_{1}^{*}\right)$ & $\left(x_{2}^{*}, y_{2}^{*}\right)$ & slope 1 & slope 2 & $\left(x_{1}^{*}, y_{1}^{*}\right)$ & $\left(x_{2}^{*}, y_{2}^{*}\right)$ & slope 1 & slope 2 \\
\hline LOW & $(41,0)$ & $(100,30)$ & 0 & .51 & $(13,0)$ & $(100,31)$ & 0 & .36 \\
\hline MIX & $(40,0)$ & $(100,27)$ & 0 & .45 & $(16,0)$ & $(75,27)$ & 0 & .46 \\
\hline SYM & $(\mathrm{x}, 2 \mathrm{x})$ & $(100,50)$ & .50 & .50 & $(\mathrm{x}, 2 \mathrm{x})$ & $(100,50)$ & .50 & .50 \\
\hline
\end{tabular}

Table 3 - Piecewise linear bid functions predicted by the risk averse Nash equilibrium (RANE) with a constant relative risk aversion parameter of $r=.5$

\begin{tabular}{|c|c|c|c|c|c|c|c|c|}
\hline \multirow[b]{2}{*}{ Treatment } & \multicolumn{4}{|c|}{ Strong } & \multicolumn{4}{|c|}{ Weak } \\
\hline & $\left(x_{1}^{*}, y_{1}^{*}\right)$ & $\left(x_{2}^{*}, y_{2}^{*}\right)$ & slope 1 & slope 2 & $\left(x_{1}^{*}, y_{1}^{*}\right)$ & $\left(x_{2}^{*}, y_{2}^{*}\right)$ & slope 1 & slope 2 \\
\hline LOW & $(29,0)$ & $(100,48)$ & 0 & .68 & $(5,0)$ & $(100,52)$ & 0 & .55 \\
\hline MIX & $(26,0)$ & $(100,46)$ & 0 & .62 & $(8,0)$ & $(75,45)$ & 0 & .67 \\
\hline SYM & $(2 x, 3 x)$ & $(100,67)$ & .67 & .67 & $(2 x, 3 x)$ & $(100,67)$ & .67 & .67 \\
\hline
\end{tabular}

\subsection{Procedures}

The experiment was conducted at the Laboratory for Experimental Economics of the University of Bonn. Most subjects were students in law or economics and were recruited by public advertisement on campus. They were required not to have participated in an auction experiment before. We considered the three treatments described above: one for low-balling (LOW), one for a mixture of low-balling and the "Getty effect" (MIX) and one for the symmetric framework (SYM). We conducted a total of 8 experimental sessions: 6 with the asymmetric treatments and 2 with the symmetric treatment. In each session, the cohort of 18 subjects was divided into 3 groups of 6 subjects. These groups were independent in the sense that subjects interacted only with the other members of their group. Each session lasted for about 3 hours. Average earnings in the experiment were DM 60 (which at that the time of the experiment were approximately equal to US\$28). 
Subjects could participate in only one session. At the outset of each session, they received instructions that were read aloud (a translation of the instructions is reported in Appendix 1) and they were provided a demonstration of the software, using values drawn from different distributions than those used in the experiments. ${ }^{8}$

Subjects were then randomly assigned to computer terminals. They were informed that they would keep their respective types for the whole experiment. In each group of subjects, three subjects were of the Strong type and three subjects were of Weak type. Each subject interacted only with the three subjects of the other type that were in her/his group. Although bidders in the SYM treatment are all of the same type, we used the same matching procedure as in the asymmetric treatments so as to keep the statistical analysis of subjects' behavior in terms of types comparable across treatments.

All subjects participated in 100 auction rounds. At the end of each auction, each participant was informed on the own value, the own bid (that resulted from applying the chosen bid function to the value), the winning bid, and the own payoff ( 0 , if they lost the auction; [value - bid], if they won). This information (including the complete own bid function) was appended to a "History" window that could be retrieved at any time during the experiment.

\section{Results}

Most of our conclusions are based on the outcomes of randomization tests for independent or related samples of independent observations (Siegel and Castellan, 1988). When we state that we have found no significant effect, we mean that the test result was not significant, even at $\alpha=.10$, one-tailed. Furthermore, we recall that after each round, subjects are randomly re-

\footnotetext{
${ }^{8}$ A screenshot of the software (based on RatImage by Abbink and Sadrieh, 1995) is included in the appendix.
} 
matched within a given group. Such a design is necessary to avoid the obvious super-game effects that would arise from the repeated interaction of the same two bidders in a series of auctions. However, such a matching scheme also implies within-group effects: a subject's behavior may be contaminated by the behavior of a previous competitor, who is not participating in the current auction. We therefore conduct most of our analysis at the group level of aggregation, and conduct tests of individual behavior whenever the independence criteria can be fulfilled.

\subsection{Bid shading, Bid ceilings and Average revenues}

\subsubsection{Bid Shading}

The extent by which bidders shade their bids is most relevant in the asymmetric treatments since in equilibrium, Strong and Weak bidders are expected to bid very differently. We test this prediction by comparing the Relative Bid Shading (henceforth, $R B S$ ) of Strong bidders to those of Weak bidders. As bidders submit complete bid functions before receiving their respective values, this measure of bid shading has to account for all possible values that a bidder can receive so that we define it as

$$
R B S_{i}^{t}=\frac{\sum_{v=0}^{\bar{v}}\left[v-b_{i}^{t}(v)\right]}{\sum_{v=0}^{\bar{v}} v} \text { for } t=1, \ldots, 100 \text { and } i=S, W
$$

Table 4 reports the average $R B S$ in each treatment. We find no significant difference across types in SYM, which is not surprising, since in this treatment all bidders (even though we call some "Strong" and others "Weak") draw their values (with replacement) from the same distribution. In the asymmetric treatments, however, Strong bidders shade their bids 
significantly more than Weak bidders (at $\alpha=.01$, one-tailed), which is in line with Proposition 3.5 of Maskin and Riley (2000a). These predictions hold when we compare the (distributions of) linear slope estimates of the observed bid functions: Strong bidders tend to submit significantly less steep bid functions than Weak bidders in the asymmetric treatments, but not in the symmetric treatment where no significant difference could be diagnosed.

We also checked whether the bid distributions of Strong bidders are stochastically greater than those of Weak bidders as implied by Proposition 3.3 of Maskin and Riley (2000a). ${ }^{9}$ We tested this hypothesis by comparing the distributions of actual bids (i.e., using the realized valuations) across bidders' types and found that bids of Strong bidders are indeed stochastically greater than those of Weak bidders in LOW and in MIX, and that they are equivalent in SYM.

\subsubsection{Bid Ceilings}

Table 4 reports the average relative deviations from the RNNE and RANE bid ceilings for each type of bidder, which are computed as $\left(y_{i 2}^{t}-y_{i 2}^{*}\right) / y_{i 2}^{*}$, with $i=1, \ldots, 100$ and $i=S, W$. A comparison of these deviations reveals no significant difference across types in any treatment. For the asymmetric settings, this indicates that the bid ceilings are somehow coordinated despite the asymmetry in subjects' preferences and the lack of communication. When compared to the RNNE bid ceilings, the observed bid ceilings are significantly greater than those predicted for the LOW and SYM treatments but we find no significant difference between observed and predicted ceilings for the MIX treatment. When compared to the

\footnotetext{
${ }^{9}$ This proposition actually predicts first-order stochastic dominance, which in this case is best approximated with non-parametric statistics that check whether one sample is stochastically greater than another or not.
} 
RANE predictions, the bid ceilings of both Strong and Weak bidders are significantly lower than predicted in all treatments.

Table 4 - Bid Shading and Bid Ceilings.

\begin{tabular}{|c|c|c|c|c|c|c|}
\hline & \multirow{2}{*}{\multicolumn{2}{|c|}{$\mathrm{RBS}^{\mathrm{a}}$}} & \multicolumn{4}{|c|}{ Relative deviations from bid ceilings } \\
\hline & & & \multicolumn{2}{|c|}{ RNNE } & \multicolumn{2}{|c|}{ RANE } \\
\hline & Strong & Weak & Strong & Weak & Strong & Weak \\
\hline $\begin{array}{c}\text { LOW } \\
\text { (9 obs) }\end{array}$ & $\begin{array}{l}.61 \\
(.11)\end{array}$ & $\begin{array}{c}.52 \\
(.08)\end{array}$ & $\begin{array}{l}.10^{* *} \\
(.21)\end{array}$ & $\begin{array}{l}.12^{* *} \\
(.21)\end{array}$ & $\begin{array}{l}-.08^{* * *} \\
(.21)\end{array}$ & $\begin{array}{l}-.09^{* *} \\
(.21)\end{array}$ \\
\hline $\begin{array}{c}\text { MIX } \\
(9 \text { obs }) \\
\end{array}$ & $\begin{array}{l}.72 \\
(.09) \\
\end{array}$ & $\begin{array}{c}.54 \\
(.11) \\
\end{array}$ & $\begin{array}{c}.00 \\
(.24) \\
\end{array}$ & $\begin{array}{c}.05 \\
(.23) \\
\end{array}$ & $\begin{array}{l}-.19^{* *} \\
(.24)\end{array}$ & $\begin{array}{l}-.19^{* *} \\
(.23)\end{array}$ \\
\hline $\begin{array}{c}\text { SYM } \\
(6 \text { obs })\end{array}$ & $\begin{array}{c}.37 \\
(.08)\end{array}$ & $\begin{array}{c}.34 \\
(.07)\end{array}$ & $\begin{array}{l}.06^{*} \\
(.16)\end{array}$ & $\begin{array}{l}.07^{* *} \\
(.12)\end{array}$ & $\begin{array}{l}-.11^{* *} \\
(.16)\end{array}$ & $\begin{array}{l}-.10^{\text {*** }} \\
(.12)\end{array}$ \\
\hline
\end{tabular}

Note: Standard deviations in parenthesis; ${ }^{\text {a }}$ Relative Bid Shading;

${ }^{* *}$ Significant at $\alpha=.05 ;{ }^{*}$ Significant at $\alpha=.10$ (one-tailed)

\subsubsection{Revenues}

Table 5 reports the observed and expected revenues. In all treatments, observed revenues are significantly greater than those expected in the RNNE (at $\alpha=.02$, one-tailed), but are not different from those expected in the RANE. The observation that revenues in SYM are closer to the RANE than to the RNNE predictions is in line with the received literature that explains overbidding in symmetric first-price auctions in terms of constant relative risk aversion.

Since the conclusions remain unchanged for the last 25 rounds of the experiment, we infer that both the behavior of Strong and Weak bidders and the revenues generated by the different treatments are consistent with the basic predictions of the Nash equilibrium models studied. 
Table 5 -Average Seller's Revenues (and Standard Deviation)

\begin{tabular}{c|c|c|c}
\hline & Observed & RNNE & RANE \\
\hline LOW & 24.87 & 12.50 & 23.06 \\
$(9$ obs $)$ & $(4.47)$ & $(.74)$ & $(1.16)$ \\
\hline MIX & 18.51 & 10.61 & 21.15 \\
$(9$ obs $)$ & $(5.35)$ & $(.33)$ & $(.56)$ \\
\hline SYM & 42.47 & 33.40 & 44.53 \\
$(6$ obs $)$ & $(3.89)$ & $(.66)$ & $(.88)$ \\
\hline
\end{tabular}

\subsection{Nash equilibrium behavior, Empirical Best Replies and shapes of bid functions}

\subsubsection{Nash Equilibrium Behavior}

The plots in Figure 1 show that the average bid functions are better tracked by the RANE prediction in the symmetric treatment than in the asymmetric treatments. In the latter, although Strong bidders bid less aggressively than Weak bidders for equal values, they overbid mostly at low values, which is inconsistent with the risk neutral or risk averse equilibrium predictions for these treatments.

To assess the explanatory power of these models, we compare the Relative Squared Deviations from the RNNE and RANE bid functions (henceforth, $R S D$ ). We define $R S D$ for bidder type $i$ in round $t$ as

$$
R S D_{i}^{t}=\frac{\sum_{v=0}^{\bar{v}}\left[b_{i}^{t}(v)-b_{i}^{*}(v)\right]^{2}}{\max \left\{\sum_{v=0}^{\bar{v}}\left[v-b_{i}^{*}(v)\right]^{2}, \sum_{v=0}^{\bar{v}}\left[-b_{i}^{*}(v)\right]^{2}\right\}} \quad \text { for } t=1, \ldots, 100 \quad \text { and } \quad i=S, W
$$

where $b_{i}^{*}(v)$ stands for the RNNE or the RANE bid function of type $i$ and the denominator for the maximum possible deviation from that strategy. 


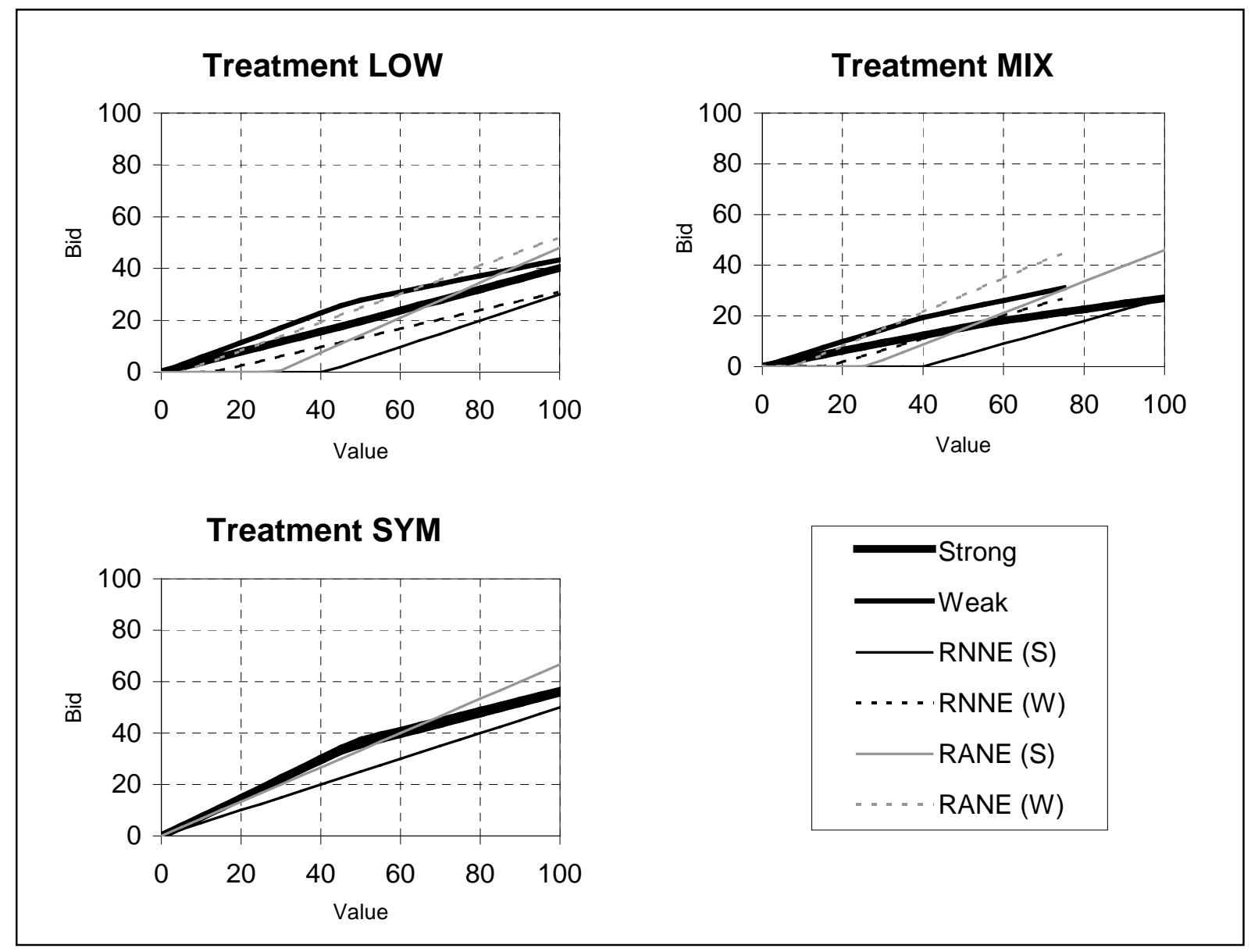

Figure 1: Average Bid Functions (all rounds)

Table 6 reports the average $R S D$ s and the test results of a comparison to the Nash equilibrium predictions we considered. The deviations from the RNNE and RANE predictions are relatively small, between $4 \%$ and $17 \%$ of the maximum possible deviations. However, those from RANE are significantly smaller than those from RNNE for both Strong and Weak bidders only in the symmetric treatment. In the asymmetric treatments, with the exception of Strong bidders in MIX for whom the RNNE model outperforms the RANE one, the two models perform equally well in explaining deviations. Deviations from RANE are also significantly smaller in the symmetric treatment than in the asymmetric ones. As these 
patterns hold in the last 25 rounds, it appears that neither of these models provides a consistent explanation of the behavior observed in the three treatments. ${ }^{10}$

Table 6 - Average RSDs from Nash Equilibrium Bid Functions (Standard Deviations)

\begin{tabular}{|c|c|c|c|c|c|c|}
\hline & \multicolumn{3}{|c|}{ Strong } & \multicolumn{3}{|c|}{ Weak } \\
\hline & RNNE & RANE & $\begin{array}{c}\text { RANE } v s \\
\text { RNNE }^{\dagger}\end{array}$ & RNNE & RANE & $\begin{array}{l}\text { RANE } v s \\
\text { RNNE }^{\dagger}\end{array}$ \\
\hline $\begin{array}{l}\text { LOW } \\
(9 \text { obs })\end{array}$ & $\begin{array}{c}.13 \\
(.07)\end{array}$ & $\begin{array}{c}.14 \\
(.07) \\
\end{array}$ & $\begin{array}{l}\text { no signif. } \\
\text { difference }\end{array}$ & $\begin{array}{c}.14 \\
(.04)\end{array}$ & $\begin{array}{c}.14 \\
(.07) \\
\end{array}$ & $\begin{array}{l}\text { no signif. } \\
\text { difference }\end{array}$ \\
\hline $\begin{array}{c}\text { MIX } \\
(9 \text { obs }) \\
\end{array}$ & $\begin{array}{c}.09 \\
(.05) \\
\end{array}$ & $\begin{array}{c}.17 \\
(.05) \\
\end{array}$ & $\mathrm{RNNE}^{* * *}$ & $\begin{array}{c}.13 \\
(.08) \\
\end{array}$ & $\begin{array}{c}.17 \\
(.10) \\
\end{array}$ & $\begin{array}{l}\text { no signif. } \\
\text { difference }\end{array}$ \\
\hline $\begin{array}{c}\text { SYM } \\
\text { (6 obs) }\end{array}$ & $\begin{array}{l}.15 \\
(.06)\end{array}$ & $\begin{array}{c}.06 \\
(.03)\end{array}$ & $\mathrm{RANE}^{*}$ & $\begin{array}{l}.15 \\
(.09)\end{array}$ & $\begin{array}{c}.04 \\
(.01)\end{array}$ & $\mathrm{RANE}^{* *}$ \\
\hline
\end{tabular}

$\dagger$ This column reports the model with significantly smaller $R S D \mathrm{~s}$.

Significance levels: ${ }^{* * *} \alpha=.01 ;{ }^{* *} \alpha=.05 ;{ }^{*} \alpha=.10$ (one-tailed)

Such significant deviations from the Nash equilibrium predictions could be due to the bidder's response mode, which is different from the one traditionally used. We therefore considered the actual valuations that bidders received in the LOW treatment and conducted the same tests as those reported in Pezanis-Christou (2002) which referred to similar LOW sessions that were conducted with the traditional design. As we find no significant difference across designs and as we reach the same conclusions, we infer that the observed behavior is not significantly affected by the response mode we used in this experiment. Also, all our conclusions for the three treatments remain unchanged when we test theoretical predictions with the actual valuations and bids.

\footnotetext{
10 For all treatments, we checked whether subjects' bidding behavior converges to the RNNE or RANE predictions. Although we find negative Spearman rank correlation coefficients (between $R S D$ s and $t$ ) for many groups, we cannot reject the null hypothesis of no convergence.
} 


\subsubsection{Empirical Best Replies}

A drawback of the analysis of deviations from a Nash equilibrium prediction is that it foregoes an assessment of the subjects' strategic behavior. Indeed, a comparison between observed and equilibrium bid functions can be misleading because the latter are unlikely to be best replies to the rivals' bid functions. We therefore follow Avery and Kagel (1997) by studying deviations from best reply bidding. ${ }^{11}$ We do so by determining for each type of bidder in each treatment, the Empirical Best Reply (EBR) function, which is the risk neutral best reply bid function to the distribution of the actual rivals' bid functions.

In contrast to previous studies that compared the observed behavior in round $t$ to an estimated best reply from the data of all rounds, our design allows us to compare, in each round, a bidder's bid $b_{i}^{t}(v)$ to the EBR bid given the valuation that this bidder received in this particular round. We compute a bidder's relative error as the ratio of the difference between the bid and the EBR bid to the bidder's valuation, and we report the aggregate distributions for each type and treatment in Figure 2. These distributions assume a bin range of 0.025 so that errors in $(-0.0125 ;+0.0125]$ are labeled as 0 ; errors in $(+0.0125 ;+0.0375]$ are labeled as 0.025 , etc. The plots indicate that although the distributions of both Strong and Weak bidders usually have a modal frequency at 0 , they are also skewed towards positive relative errors, especially for Strong bidders in the LOW treatment. In this treatment, the modal frequency of Strong bidders is at 0.5 , followed by 0.4 and 0 .

\footnotetext{
${ }^{11}$ Avery and Kagel (1997) look at deviations from EBR payoffs in their " $\varepsilon$-equilibrium" analysis of behavior in second-price auction experiments with common-values and asymmetric private advantages. Fudenberg and Levine (1997) look at deviations from EBR payoffs in their " $\varepsilon$-self-confirming equilibrium" analysis of simple extensive-form game experiments. Selten, Abbink, Buchta and Sadrieh (2002) look at deviations from EBR payoffs in their "best reply ratio" analysis of 3x3 normal-form game experiments. Because we observe subjects' complete bid-functions and because the values are drawn (with replacement) from a uniform distributions, comparing (squared) deviations from EBR functions is analogous to comparing deviations from EBR payoffs.
} 


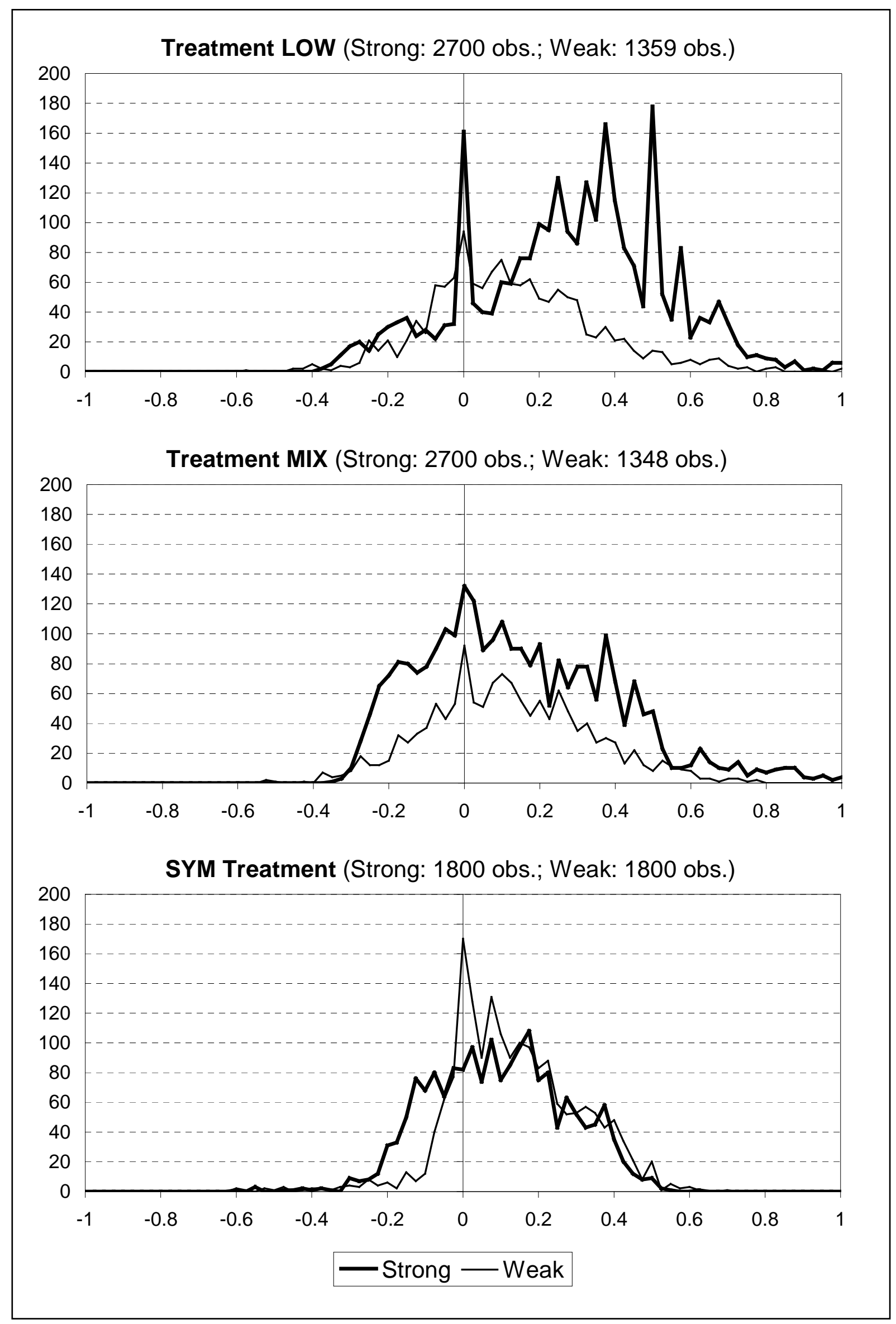

Figure 2: Aggregate Distributions of Relative Errors 
Table 7 reports summary statistics on the group distributions of relative errors in each treatment. Deviations from risk neutral best reply bids are significantly different across types (at $\alpha=.05$, two-tailed) only in the LOW treatment; with Strong bidders making larger relative errors than Weak bidders. Across treatments, Strong bidders deviate significantly more in LOW than in MIX or SYM; otherwise we find no significant difference in the relative deviations of Strong and Weak bidders. The relative frequencies of " 0 relative errors" represent less than $10 \%$ of all observations for a given type/treatment configuration and we did not find significant differences across bidders' types or treatments. In the last 25 rounds of the experiments, we find no significant difference in the behavior of Strong bidders when the LOW and MIX treatments are compared, and our conclusions about cross-treatment comparisons remain unchanged. ${ }^{12}$

Table 7 - Average Relative Deviations from Risk Neutral Best-Reply Bidding.

\begin{tabular}{c|c|c|c|c}
\hline & \multicolumn{2}{|c|}{ Strong } & \multicolumn{2}{c}{ Weak } \\
\hline & Error & \% of "0 errors" & Error & \% of "0 errors" \\
\hline LOW & .28 & 5.96 & .13 & 6.88 \\
$(9 \mathrm{obs})$ & $(.13)$ & $(4.77)$ & $(.08)$ & $(4.47)$ \\
\hline MIX & .14 & 4.89 & .12 & 6.79 \\
$(9 \mathrm{obs})$ & $(.13)$ & $(2.21)$ & $(.08)$ & $(2.37)$ \\
\hline SYM & .09 & 4.56 & .14 & 9.44 \\
$(6 \mathrm{obs})$ & $(.06)$ & $(1.00)$ & $(.08)$ & $(4.76)$ \\
\hline
\end{tabular}

Such significant cross-treatment differences allude more to type- or environment-specific patterns than to a pattern that is inherent to bidders' preferences. The finding of skewed distributions can equally result from bidders' heterogeneous behavior, whether it is ad hoc or rational (as assumed by the CRRA model for heterogeneous bidders of Cox et al., 1988), as from a homogenous misbehavior such as the miscalculation of winning probabilities and/or a

\footnotetext{
${ }^{12}$ We also considered bidders' errors instead of bidders' relative errors and reached similar conclusions.
} 
"joy of winning" as studied by Goeree et al. (2002) in the context of QRE models. In the next section, we check whether any of the EBR, the RNNE and the RANE outperforms the others in explaining the shapes of the submitted bid functions.

\subsubsection{Shapes of Bid Functions}

As subjects submitted complete bid functions in every round, the classification of bid functions in different shapes is straightforward. We categorize them into four possible shapes: Concave, Convex, Linear, and Humped. We assume a bid function to be concave if $\left(\mathrm{s}_{1}-\mathrm{s}_{2}\right) / \mathrm{s}_{1}$ $>.05$ and $s_{2} \geq 0$, where $s_{1}$ and $s_{2}$ stand for the slopes of the first and second segments of the piecewise linear bid function. We define a bid function as convex if $\left(\mathrm{s}_{1}-\mathrm{s}_{2}\right) / \mathrm{s}_{1}<-.05$; as linear if $\left|\left(\mathrm{s}_{1}-\mathrm{s}_{2}\right) / \mathrm{s}_{1}\right| \leq .05$ and as humped if $\left(\mathrm{s}_{1}-\mathrm{s}_{2}\right) / \mathrm{s}_{1}>.05$ and $\mathrm{s}_{2}<0$. A comparison of the relative frequencies of each shape to the relative frequencies of EBR shapes allows an additional qualitative assessment of the extent of strategic behavior.

\subsubsection{Asymmetric Treatments}

Figure 3 reports the relative frequencies of each shape in the asymmetric treatments, together with the proportion of submitted bid functions that have a shape matching the one of the EBR in a particular round $t$. In both treatments, the shapes of observed and EBR functions are mostly convex for Strong bidders (about $49 \%$ of all their bid functions) and concave for Weak bidders (about $49 \%$ of all their bid functions). Convex-shaped bid functions for Strong bidders match the Nash equilibrium predictions and represent $82 \%$ of all EBR functions. In both treatments, such matched cases with convex bid functions accounted for about $40 \%$ of the Strong bidders' observed strategies. The upper panels of Figure 4 report the plots of average convex bid functions and indicate that Strong bidders did not low-ball enough when 
compared to the RNNE or RANE predictions. Interestingly, the average shape of convex EBR functions is almost identical to the one predicted in the RNNE for both treatments (cf. Figure 1) so that the low-balling prediction of Maskin and Riley (2000a) is empirically robust to the behavior of Weak bidders.

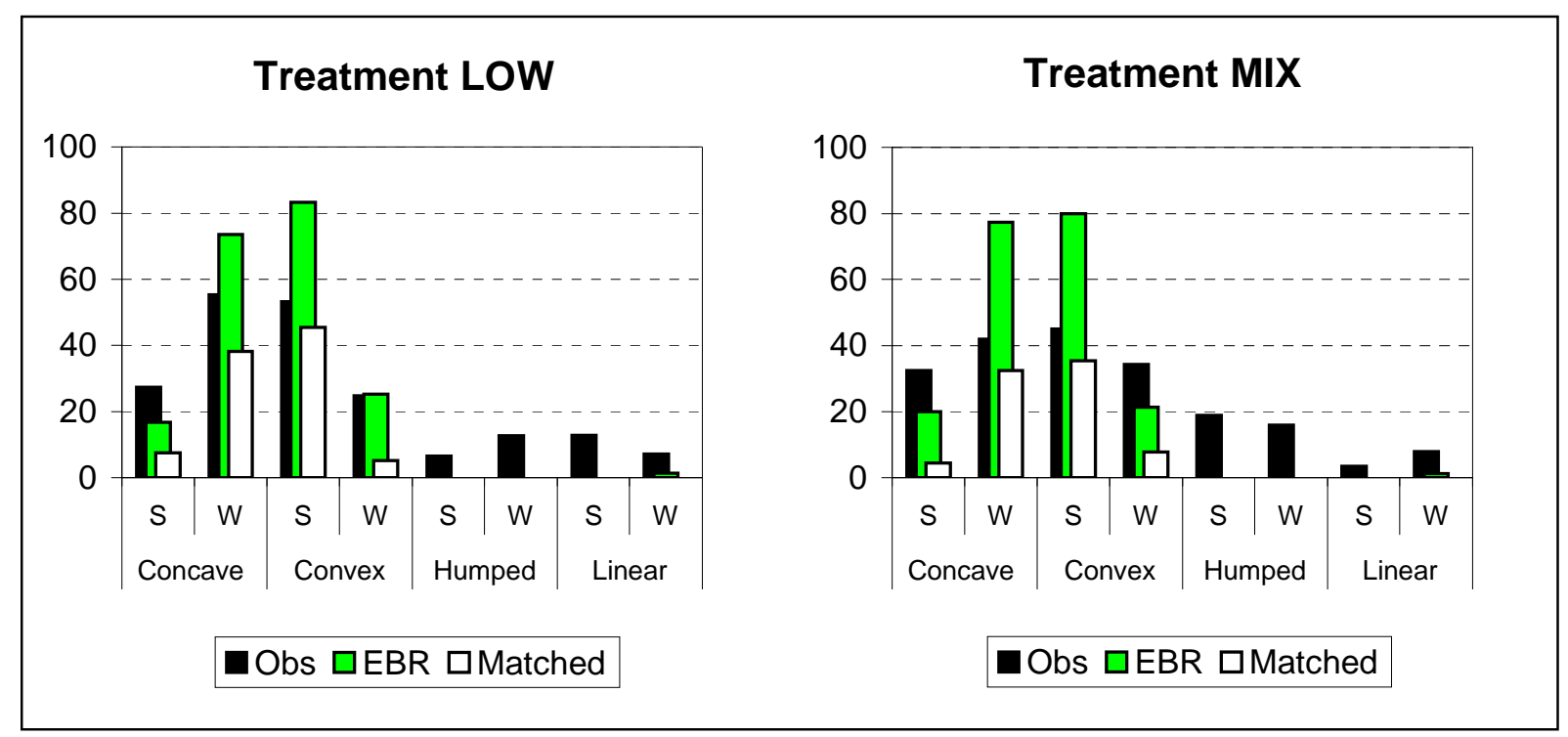

Figure 3: Distribution of bid function shapes in LOW and MIX (S: Strong, W: Weak)

The submission of concave bid functions by Weak bidders (49\%) is not supported by the RANE (or RNNE) prediction. However, such a shape is frequently recommended as a bestreply to the observed behavior of Strong bidders, since $75 \%$ of all EBR functions for Weak bidders are concave. In both treatments, such matched cases with concave functions constitute about $40 \%$ of all bid functions submitted by Weak bidders. Furthermore, while Nash equilibrium predicts convex bid functions for Weak bidders in both treatments, the observed and the EBR functions are convex in only about $20 \%$ to $30 \%$ of the cases. The plots in the lower panels of Figure 4 reveal a close fit of the shape of the average concave bid functions to 
the shape of the average concave EBR functions. ${ }^{13}$ To this extent, submitting a concave bid function is more characteristic of a best-reply to the Strong bidders' lack of low-balling than submitting a convex bid function as predicted by the Nash equilibrium.

Such bid patterns, which remain virtually unchanged for the last 25 rounds of the experiment, suggest that from a theoretical perspective, the Nash equilibrium predictions for Strong bidders are more robust to the out-of-equilibrium behavior of Weak bidders than what the predictions for Weak bidders are to the out-of-equilibrium behavior of Strong bidders. From an empirical point of view, the observed behavior suggests that the lack of low-balling by Strong bidders is the main reason for not observing the predicted outcomes.

\subsubsection{Symmetric Treatment}

The left-hand panel of Figure 5 reports the relative frequencies of each shape in the SYM treatment. About $73 \%$ of all bid functions are concave and only $10 \%$ have the linear shape predicted by RNNE and RANE. The submission of concave bid functions appears to be consistent with best-reply bidding since this shape represents $84 \%$ of all EBR functions. The frequencies of matched (observed and EBR) Concave shapes are also the highest in this treatment and represent about $60 \%$ of all submitted bid functions. The plots in Figure 6 further indicate that these concave bid functions share the non-linear characteristics of bestreply bidding. As these patterns remain unchanged for the last 25 rounds of the experiment, the data clearly indicate that the submission of linear bid functions, as predicted by RNNE and RANE, is not robust to the out-of-equilibrium behavior of competitors.

\footnotetext{
${ }^{13}$ The plots of Weak (Strong) bidders are virtually identical to those of concave (convex) bid functions that
} 


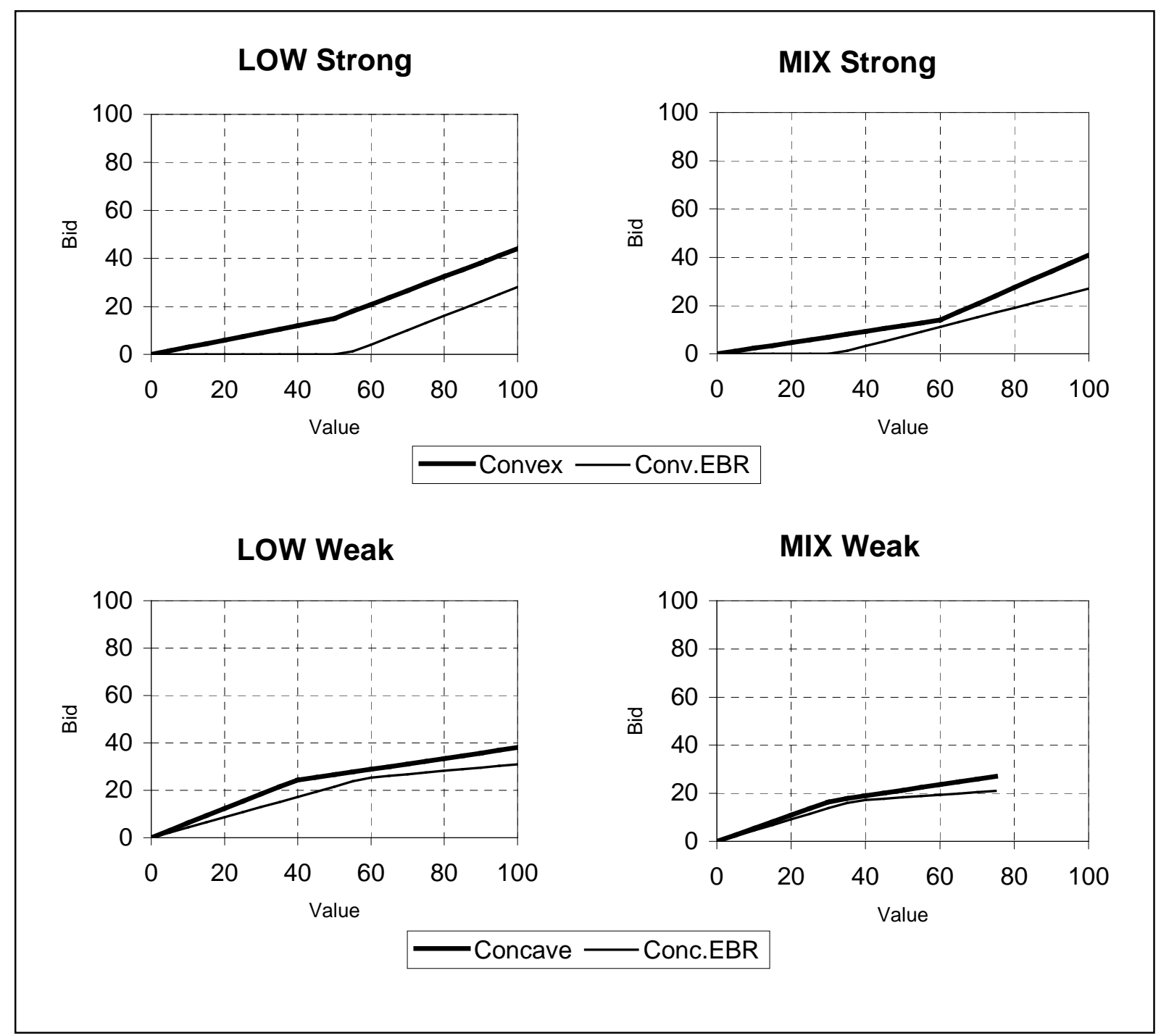

Figure 4: Average Concave and Convex Bid Functions in LOW and MIX

In the symmetric setting, the submission of concave bid functions may be consistent with the CRRA model of Cox et al. (1988), which assumes heterogeneity in the bidders' risk attitudes. In that model, bidder $i$ 's utility function is defined as $\left(v_{i}-b\right)^{r_{i}}$, with $r_{i}$ i.i.d. according to $G:\left[0, r_{\max }\right]$ and where $r_{\max }$ stands for the coefficient of the less risk averse bidder. If valuations are uniformly drawn, the CRRA equilibrium strategies are linear and can be determined only up to a maximum bid $\bar{b}$, which is itself determined by the number of bidders 
and $r_{\max }$ as $\bar{b}=(n-1) /\left(n-1+r_{\max }\right)$. The slopes of the linear part of these bid functions are greater than the slope of the RNNE bid function (i.e., greater than 0.5). As most previous experiments report a significant overbidding, $r_{\max }$ is usually set equal to 1 so that in our case $\bar{b}=50$. For bids greater than $\bar{b}$ these equilibrium strategies have to be approximated numerically (Van Boening, Rassenti and Smith, 1998). However, an interesting property of the CRRA model is that when valuations are drawn from a uniform distribution, then, for a given $r_{\max }$, the linear parts of the CRRA bid functions are invariant to the distribution of risk parameters so that we only need to specify the support of the distribution of risk parameters to determine them. To this extent, the testing of the CRRA hypothesis would almost revert to the testing of a belief-free model in the sense of Chen and Plott (1998). As the CRRA model predicts concave bid functions for $r_{i}<1$, it could therefore provide a good fit of the observed behavior. ${ }^{14}$ We recall that the random matching of subjects in our experiment prevents the assessment of individual behavior so that we only check for a qualitative fit of this model rather than estimating the individual CRRA parameters.

The data reported in the right-hand panel of Figure 5 indicates that CRRA bid functions represent about $18 \%$ of all bid functions whereas non-CRRA concave functions represent about $60 \%$ of them. A similar ratio of CRRA-to-concave bid functions is observed for the EBR functions (23\% vs. $61 \%$ ) and the matching frequencies also show sharp differences in favor of the submission of non-CRRA concave bid functions. To this extent, the latter would better represent best-reply bidding than CRRA or RANE bid functions.

\footnotetext{
${ }^{14}$ Cox et al. (1988) and Cox and Oaxaca (1996) report some non-linearity (concavity) in the estimated bid functions, but conclude that it is generally insignificant and that the data are best explained by linear bid functions. However, Pezanis-Christou and Romeu (2002) use structural econometric methods and show that these non-linearities are often significant and that the observed heterogeneity in behavior usually implies a rejection of the CRRA model of bidding. Selten and Buchta (1998) also report non-linear bid functions, many of which displaying a concavity in their shapes.
} 


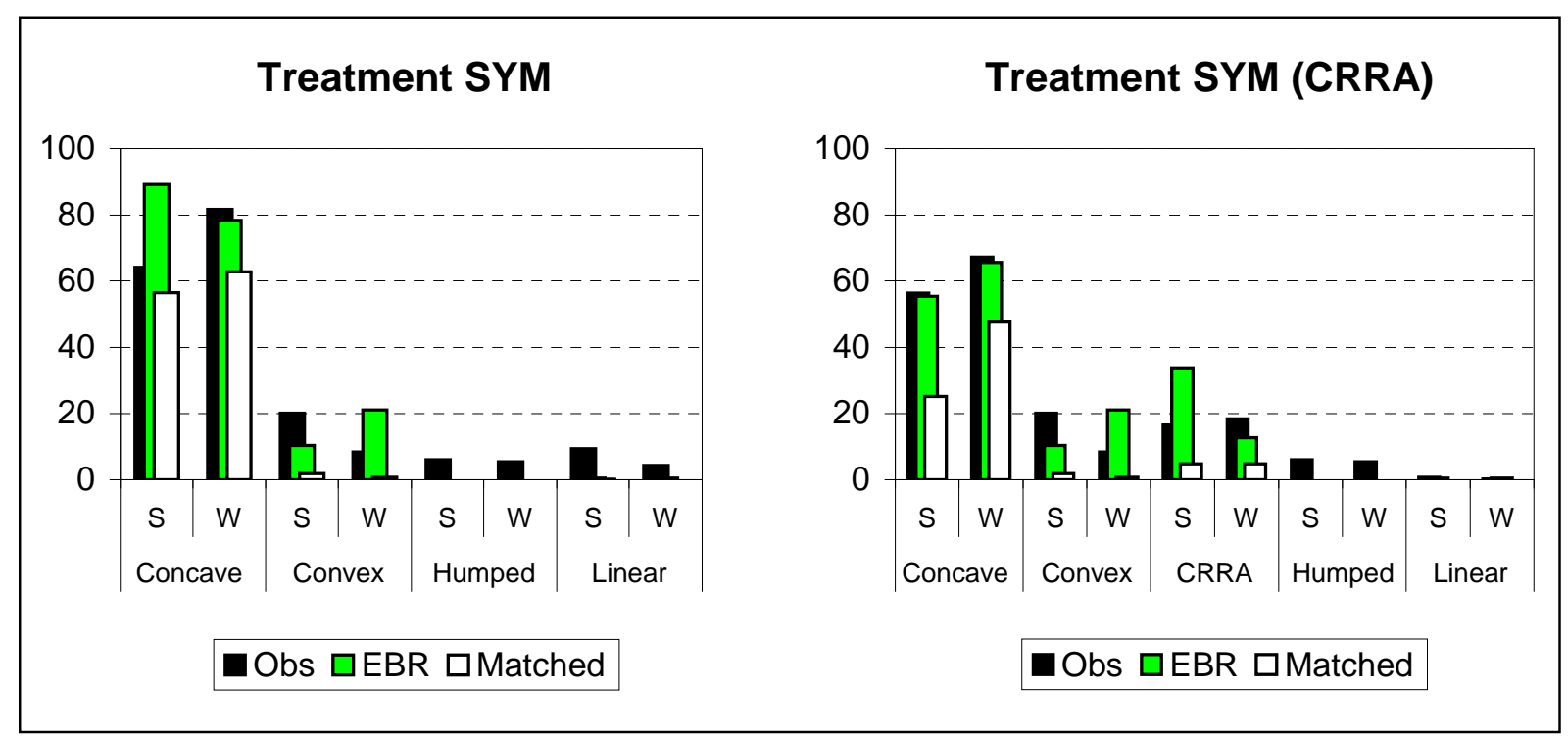

Figure 5: Distribution of bid function shapes in SYM

For each bidder, we count the number of rounds in which she/he submitted a CRRA bid function, assuming $\bar{b}=50$ (i.e., $r_{\max }=1$ ). A bid functions qualifies as a "CRRA bid function" if it is linear with $\mathrm{s}_{1} \geq .5, \mathrm{~s}_{2} \geq 0$ and $\mathrm{y}_{2} \geq 50$ or concave with $\mathrm{s}_{1} \geq .5,0 \leq \mathrm{s}_{2}<\mathrm{s}_{1}$, $\bar{b}=50, \mathrm{y}_{1} \geq \bar{b}$ and $\mathrm{y}_{2} \geq \bar{b}$. It appears that for 28 out of 36 subjects who ever submitted CRRA bid functions, the average rate of submission of such bid functions is $22 \%$. We test the null hypothesis that the probability for a bidder to submit a CRRA bid function is equal to 0.5 against the alternative that it is smaller than 0.5. According to the Binomial test, we cannot reject this hypothesis for only 6 subjects (at $\alpha=.05$ one-tailed). When the test is conducted over the last 25 rounds, we cannot reject the null of CRRA bidding for one more bidder and the modal frequency is still on Concave (i.e., about $70 \%$ of all bid functions). Therefore, as, 6 or 7 CRRA bidders out of 36 do not represent a significant rate of success according to the Binomial test, we infer that subjects are not likely to submit CRRA bid functions. We also tested a softer version of the CRRA model which assumes $y_{1}>40$ so that we allow for a nonlinearity at $\bar{b}>40$ instead of the critical $\bar{b}=50$. In this case the mode of the distribution of shapes remains on Concave (57\%, followed by CRRA: $31 \%$ ) and we cannot reject the null of 
CRRA bidding for 11 subjects (and for 12 subjects in the last 25 rounds), which does not represent a significant success rate according to the Binomial test either.

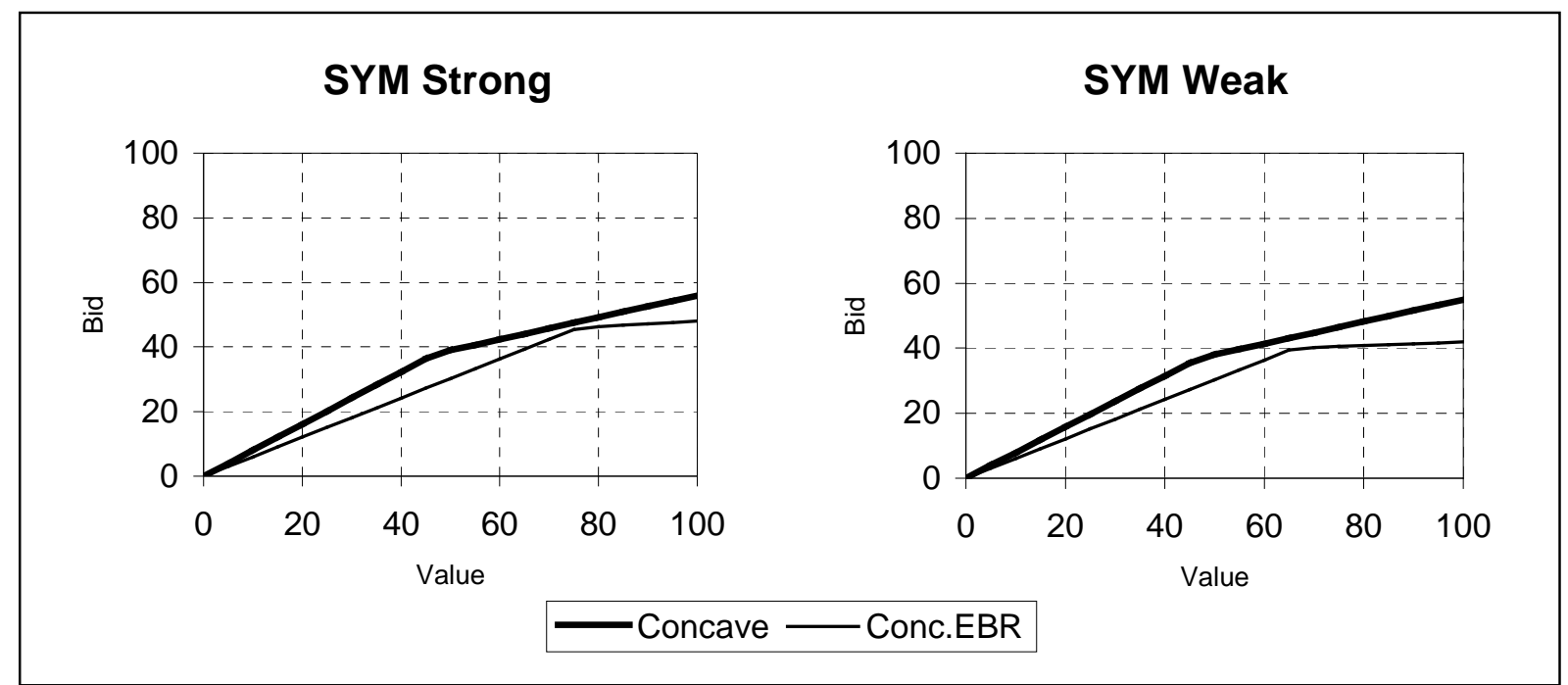

Figure 6: Average Concave Bid Functions in SYM

As far as the frequency of matched shapes can be used as a proxy for best-reply behavior, the above analysis in terms of (four possible) shapes would suggest that the extent of best-reply behavior is roughly the same across types within a treatment but that it changes across treatments, especially between symmetric and asymmetric treatments. In the aggregate, the observed shapes match the EBR ones in $48 \%$ of times in LOW, in $40 \%$ of times in MIX and in $61 \%$ of times in SYM, so that subjects would be closer to best reply bidding in symmetric settings than in the more complex bidding environment of asymmetric settings.

\section{Summary and Conclusion}

We report on a series of experiments that were designed to assess the strategic considerations that underlie the Nash equilibrium predictions for first-price sealed bid auctions with independent private values. The outcomes indicate that the observed behavior supports the basic Nash equilibrium predictions for risk neutral or risk averse bidders: $i$ ) Strong bidders bid less aggressively than Weak bidders in the asymmetric bidding environments but not in the 
symmetric one, where no significant difference across bidders' (pseudo-)types are expected or observed; ii) both types of bidders submit similar bid ceilings, whether the auction is symmetric or not; iii) the observed revenues are not significantly different from those predicted by a Nash equilibrium model for constant relative risk averse bidders and iv) aggregate behavior in symmetric auctions is best explained by a Nash equilibrium model for the constant absolute risk averse bidders and the one of asymmetric auctions is equally well explained by a Nash model for risk neutral or homogenous constant relative risk averse bidders.

However, when we compare the shapes of the individual bid functions to the shapes of bestreply bid functions, then the data is much less supportive of the Nash equilibrium predictions. In the symmetric environment, bid functions are mostly concave and they match the concave shape of the (risk neutral) best-reply bid function in $60 \%$ of the time. Hence, although such a behavior is neither in line with the Nash equilibrium predictions for homogenous nor for heterogeneous bidders with constant relative risk aversion (cf. Cox et al. 1982, 1988), it does display clear characteristics of best-reply behavior. In the asymmetric bidding environments, Strong bidders submit convex bid functions about half of the time but they do not "low-ball" enough when compared to the Nash equilibrium predictions. This lack of low-balling is not supported by best-reply behavior since the latter recommends $80 \%$ of the time bid functions that are, on average, very similar to the risk neutral Nash equilibrium prediction. To the contrary, Weak bidders submit concave bid functions about half of the time, which are not supported by the Nash equilibrium. They do, however, match the characteristics of a bestreply behavior that recommends concave functions about $75 \%$ of the time.

The outcomes of our experiment thus suggest that bidders' behavior is more governed by strategic considerations than by ad hoc bidding rules. Such strategic considerations are more 
evident in a symmetric environment than in the asymmetric environments that we considered. Although the received Nash equilibrium models are well supported only in the aggregate, our analysis of the asymmetric bidding environments indicates that the low-balling predictions of Maskin and Riley (2000a) are remarkably robust to the out-of-equilibrium behavior of Weak bidders. To this extent, we can conjecture that a necessary condition to observe the revenue implications of bidders' asymmetric preferences is that Strong bidders do indeed low-ball as expected. 


\section{References}

Abbink K. and A. Sadrieh, 1995, "RatImage - Research assistance toolbox for computeraided human behavior experiments", SFB 303 Discussion Paper No. B-325, University of Bonn.

Avery C. and J.H. Kagel, 1997, "Second-Price Auctions with Asymmetric Payoffs: An Experimental Investigation ", Journal of Economics and Management Strategy, 6(3), 573-603

Cox J.C. and R.L. Oaxaca, 1996, "Is bidding behavior consistent with bidding theory for private value auctions", in R. Mark Isaac (ed.), Research in Experimental Economics, vol. 6, Greenwich, CT: JAI Press, pp 131-148.

Cox J.C., B. Roberson and V.L. Smith, 1982, "Theory and behavior of single object auctions", in V.L. Smith (ed.), Research in Experimental Economics, vol. 2, Greenwich, CT: JAI Press, pp 1-43.

Cox J.C., V.L. Smith and J. Walker, 1988, "Theory and individual behavior of first-price auctions", Journal of Risk and Uncertainty, 1, 61-99.

Chen K.-Y. and C.R. Plott, 1998, "Nonlinear behavior in sealed bid first price auctions", Games and Economic Behavior, 25, 34-78.

Corns A. and A. Schotter, 1999, "Can affirmative action be cost effective: An experimental examination of price-preference auctions", American Economic Review, 89(1), 291-305.

Fudenberg D. and D.K. Levine, 1997, "Measuring Players' Losses in Experimental Games", Quarterly Journal of Economics, 112, 507-536.

Goeree J.K., C.A. Holt and T.R. Palfrey, 2002, "Quantal response equilibrium and overbidding in private-value auctions", Journal of Economic Theory, forthcoming.

Güth W., R. Ivanova-Stenzel, M. Konigstein and M. Strobel, 2002, "Learning to bid --- An Experimental Study of Bid Function Adjustments in Auctions and Fair Division Games", Economic Journal, forthcoming.

Güth W., R. Ivanova-Stenzel and E. Wolfstetter, 2002, "Bidding Behaviour at Asymmetric Auctions: An Experimental Study", European Economic Review, forthcoming.

Harrison G.W., 1990, "Risk attitudes in first-price auction experiments: a bayesian analysis", Review of Economics and Statistics, 541-546.

Harsanyi J.C., and R. Selten, 1988, "A General Theory of Equilibrium Selection in Games", Cambridge, MA: MIT Press.

Kagel J.H., 1995, “Auctions: a survey of experimental research”, in J. Kagel and A. Roth (eds.), The Handbook of Experimental Economics, Cambridge, MA: MIT Press.

Kagel J.H., R.M. Harstad and D. Levin, 1987, "Information impact and allocation rules in auctions with affiliated private values: a laboratory study", Econometrica, 55(6), 1275 1304.

Landsberger M., J. Rubinstein, E. Wolfstetter and S. Zamir, 1999, "First-price auctions when the ranking of buyers is common knowledge", Review of Economic Design, forthcoming.

Lebrun B., 1999, "First-price auctions in the N asymmetric case", International Economic Review, 40, 125-142. 
Li H. and J.G. Riley, 1999, "Auction choice”, mimeo, Hong Kong University of Technology and University of California at Los Angeles.

Marshall R.C., M.J. Meurer, J.-F. Richard and W. Stromquist, 1994, "Numerical analysis of asymmetric first-price auctions ", Games and Economic Behavior, 7, 193-220.

Maskin E. and J.G. Riley, 2000a, "Asymmetric Auctions", Review of Economic Studies, 67, 413-438.

Maskin E. and J.G. Riley, 2000b, "Uniqueness in Sealed High Bid Auctions", Review of Economic Studies, 67, 439-454.

Pezanis-Christou P., 2002, "On the impact of low-balling: Experimental results in asymmetric auctions", International Journal of Game Theory, 31, 69-89.

Pezanis-Christou P. and A. Romeu, 2002, "Structural Inferences from First-Price Auction Experiments”, IAE-UAB Working Paper \#531-02.

Plum M., 1992, "Characterization and Computation of Nash-Equilibria for Auctions with Incomplete Information", International Journal of Game Theory, 20, 393-418.

Selten R., K. Abbink, J. Buchta and A. Sadrieh, 2002, "Playing 3 x 3 Normal Form Games", Games and Economic Behavior, forthcoming.

Selten R. and J. Buchta, 1998, "Experimental sealed bid first price auctions with directly observed bid functions", in O.D. Budescu, I. Erev and R. Zwick (eds.), Games and Human Behavior - Essays in Honor of Amon Rapoport, Mahwah (N.J.): Lawrence Erlbaum Ass.

Siegel S. and J. Castellan, 1988, "Nonparametric statistics for the behavioral sciences", McGraw Hill.

Van Boening M.V., S.J. Rassenti and V.L. Smith, 1998, "Numerical computation of equilibrium bid functions in a first-price auction with heterogeneous risk attitudes", Experimental Economics, 1(2), 147-159.

Vickrey W., 1961, “Counterspeculation, auctions, and competitive sealed tenders", Journal of Finance, 16, 8-37. 


\section{Appendix 1 - Instructions}

\section{Brief Outline}

Each of you is about to particpate in a series of 100 auctions.

In each auction, you are randomly matched with one other participant whose identity is unknown to you.

In each auction, a hypothetical item is sold either to you or to the other participant.

You receive the item if your bid is the higher bid submitted.

You make a gain (profit) if you receive the item and if your bid is smaller than your resale value.

The resale value for each of the 100 items that you will bid for is randomly drawn from a given range.

\section{Bidder Types}

Before the experiment starts, each participant draws a card that detrmines her/his type : You will either be a Atype or a B-type bidder.

Your type remains the same throughout the experiment.

If you are a A-type, in each auction, your resale value is drawn with an equally likely chance from the range $[0 ; 100]$.

If you are a B-type, in each auction, your resale value is drawn with an equally likely chance from the range [$100 ; 100]$.

A A-type bidder is always matched with a B-type bidder and vice-versa.

\section{Submitting the Bid Function}

A bid function specifies a bid for every possible resale value between 0 and 100. A bid cannot be greater than its corresponding resale value.

Your bid function always consists of 2 lines connecting the 3 points B0, Bv and Bmax.

. The point B0 specifies the bid that you submit if you receive the resale value 0 . This bid is always equal to 0 .

. The point Bv specifies the bid you submit if you receive the resale value $\mathrm{v}$, which is any arbitrary value between 1 and 99 .

. The point Bmax specifies the bid you submit if you receive the resale value 100.

. The bid that you submit if you receive a resale value between 0 and $\mathrm{v}$ is determined by the line connecting B0 and Bv. Similarly, the bidthat you submit if you receive a resale value between $\mathrm{v}$ and 100 is determined by the line connecting $\mathrm{Bv}$ and Bmax.

Your task is to choose Bv and Bmax at the outset of each auction, before your resale value is drawn.

Each bidder knows his own bid function but not the one of the other participant.

\section{Resale Values and Bids}

After you have chosen your bid function, your resale value for the current auction is randomly drawn.

Once your resale value is drawn, one of the following two situations occurs :

If your resale value is smaller than 0 (which can happen only to B-type bidders), you cannot submit a bid.

If your resale value is greater or equal to 0 , your bid is determined by your bid function and is automatically submitted.

\section{Awards}

If only one of the bidders could submit a bid, she/he is awarded the item.

If both bidders could submit a bid, the one with the higher bid is warded the item.

If both bidders submit the same bid, one of them will be randomly chosen (each with probability of one half) to be awarded the item.

The bidder who is awarded the item makes a gain which is equal to his resale value minus the bid. 
The bidder who is not awarded the item makes no gain.

\section{Payoffs}

Your total profit from participating in this experiment is equal to the sum of your gains in the auction.

Your total profit is exchanged at the rate of 0.04DM per point.

\section{Appendix 2 - Screen shot}

Screen shot of a strong bidder's terminal in the treatment LOW. The presented auction is fictitious. Auction 3 (called "round 3" in the experiment) has just elapsed. The next auction begins as soon as all participants have pressed the "continue" button.

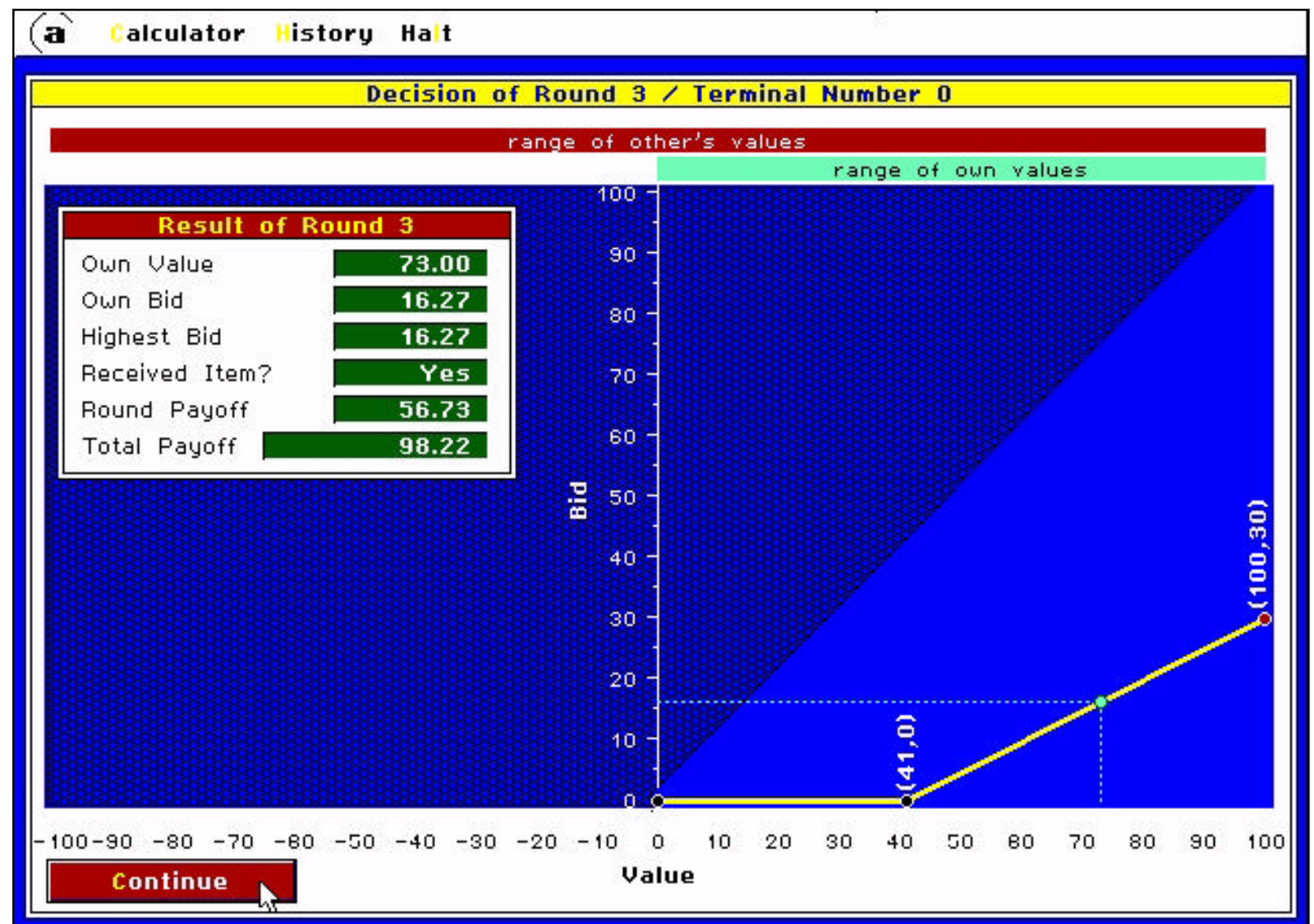

i. Click the Continue button or press $c$ to continue. 